\title{
(9)
}

\section{Equação e Conhecimento Matemático para o Ensino: relações e potencialidades para a Educação Matemática}

\section{Equation and Mathematical Knowledge for Teaching: relations and potentialities for Mathematics Education}

Alessandro Jacques Ribeiro*

\section{Resumo}

A noção de conhecimento matemático para o ensino, desenvolvida por Deborah Ball e seus colaboradores, surgiu a partir dos trabalhos de Shulman acerca do conhecimento pedagógico do conteúdo. O conhecimento matemático para o ensino refere-se a um tipo de conhecimento necessário para o professor poder desenvolver a sua "tarefa" de ensinar matemática. No presente ensaio teórico, pretende-se apontar relações e potencialidades entre diferentes significados de equação - concebidos a partir dos trabalhos de Alessandro Ribeiro - e o conhecimento matemático para o ensino, no caso do conceito de equação. Nesse sentido, desenvolveram-se análises dos resultados de pesquisas que contemplam tais significados à luz do modelo teórico proposto por Ball. Dentre os principais resultados, observaram-se as convergências entre tais estudos, reconhecendo potencialidades que a abordagem de diferentes significados de equação pode propiciar para a constituição do conhecimento matemático para o ensino de equações, por exemplo, a partir da epistemologia do conceito de equação.

Palavras-chave: Equação. Conhecimento Matemático para o Ensino. Educação Algébrica. Formação de Professores. Ensaio Teórico.

\footnotetext{
* Doutor em Educação Matemática pela Pontifícia Universidade Católica (PUC/SP). Professor Adjunto lotado no Centro de Matemática, Computação e Cognição (CMCC) da Universidade Federal do ABC (UFABC), Santo André, SP, Brasil. Endereço para correspondência: Rua Santa Adélia, 166 - Bloco A, sala 534, Bairro Bangú, CEP: 09210-170, Santo André, SP, Brasil. E-mail: alessandro.ribeiro@ufabc.edu.br.
} 


\begin{abstract}
The notion of mathematical knowledge for teaching, developed by Deborah Ball and her colleagues, emerged from Shulman's works on pedagogical content knowledge. Mathematical knowledge for teaching refers to a kind of knowledge teachers need to develop their "tasks" in teaching mathematics. In this paper, we seek to point out relations between different meanings of equation, conceptualized based on the work of Alessandro Ribeiro, and their potentialities with respect to mathematical knowledge for teaching, in the case of the concept of equation. Research results were analyzed based on those meanings in the light of the theoretical model proposed by Ball. Similarities between the studies were observed, recognizing the potential that addressing different meanings of equation can provide for the construction of mathematical knowledge for teaching equations, particularly from the epistemology of the concept of equation.
\end{abstract}

Keywords: Equation. Mathematical Knowledge for Teaching. Educational Algebra. Teacher Teaching. Theoritical Essay.

\title{
1 Introdução
}

A problemática que se constitui neste trabalho surgiu no seio de uma preocupação emergente na área da Educação Matemática - trazer para o ambiente da formação do professor de Matemática uma discussão sobre temas da Educação Básica que não contemple um simples caráter de revisão e retomada de conteúdos fundamentais (RIBEIRO; MACHADO, 2009). Defende-se o argumento de que uma abordagem de ensino fundamentada em discussões epistemológicas e/ou didático-pedagógicas de conceitos matemáticos pode propiciar a ampliação dos conhecimentos que os professores possuam acerca desses conceitos matemáticos (ARTIGUE et al., 2001).

Estarão aqui apresentados e discutidos diferentes significados do conceito de equação (RIBEIRO, 2007; BARBOSA, 2009; DORIGO, 2010; STEMPNIAK, 2011). Pretende-se relacionar o desenvolvimento e os resultados de tais pesquisas com as elaborações teóricas de Shulman (1986) e de Ball, Thames e Phelps (2008).

A delimitação da região de inquérito em torno do conceito equação é ratificada pela emergência de desenvolver pesquisas que tenham a preocupação de investigar os conhecimentos do professor de matemática que ensina Álgebra (DOERR, 2004). A autora ressalta em seu trabalho "a carência de um corpo substancial de pesquisas sobre o conhecimento e a prática do professor no ensino de Álgebra" (DOERR, 2004, p. 268). 


\section{Discutindo o problema de pesquisa}

Analisando resultados de diferentes pesquisas em Educação Matemática, em particular aquelas que discutem o ensino e a aprendizagem de Álgebra, observa-se que o debate contempla enfoques e pontos de vista diversos. Existem pesquisas que investigam as dificuldades no equacionamento de problemas (COTRET, 1997; ALMEIDA, 2006); as que investigam diferentes estratégias para a resolução de alguns tipos de equação (RIBEIRO, 2001; LIMA, 2007); as que investigam o conhecimento dos professores sobre Álgebra e sobre equações (ATTORPS, 2003; FIGUEIREDO, 2007; LI, 2007), e aquelas que investigam o papel da Álgebra e das equações no currículo (PONTE, 2004; KILPATRICK; IZSÁK; 2008).

Tais pesquisas são apenas parte de muitos trabalhos desenvolvidos, no Brasil e no mundo, em torno da temática da Educação algébrica. A escolha destes estudos pautou-se no objetivo de fundamentar a problemática que se constrói no presente trabalho; problemática, essa, que busca relacionar diferentes significados de equação (RIBEIRO, 2007) e o conhecimento matemático para o ensino (BALL; THAMES; PHELPS, 2008). Alguns dos resultados e das conclusões das pesquisas acima elencadas passam, agora, a ser explorados, no intuito de desvelar a problemática que permeia o presente trabalho.

Cotret (1997), em sua pesquisa sobre os problemas e as dificuldades que surgem no equacionamento de problemas escritos, discute a pertinência e a adequação das equações que são usadas para modelar problemas intra e extra Matemática. Reconhece que, muitas vezes, não sabemos justificar a escolha de um determinado modelo de equação para representar certo problema, a não ser pela resolução e pela busca da resposta do problema. Afirma que as pessoas não sabem justificar o porquê de terem escolhido tal modelo, nem têm certeza de ser esse modelo o mais eficaz naquela situação, a menos que recorram à resolução da equação.

Attorps (2003) desenvolveu uma pesquisa, com dez professores secundários, sobre suas concepções a respeito da noção de equação. O trabalho Teachers' images of the 'equation' concept traz resultados muito importantes e contributivos para o problema de pesquisa que se aborda neste artigo, na medida em que discute concepções de equação presentes no trabalho dos professores. Durante as entrevistas realizadas em sua pesquisa, Attorps apresenta aos professores cinco categorias de expressões que não são equações e uma que é equação. Em síntese, os resultados parecem indicar que os professores, 
em primeiro lugar, nem sempre associam equação à igualdade, o que normalmente ocorria quando se tratava de equações triviais. Outro resultado interessante foi o fato de que, alguns deles, não reconhecem uma determinada expressão como uma equação, por não saberem como encontrar a solução. Finalizando, a pesquisadora observou, ainda, que, em grande parte, os professores têm uma concepção de equação muito ligada à questão procedimental - as técnicas e os procedimentos para sua resolução. Durante as entrevistas, ela pôde observar que a concepção desses professores sobre ensino de equação parecia ter como origem a forma como eles aprenderam a trabalhar com o processo de resolução de equações - suas experiências enquanto alunos.

Ponte (2004), em seu trabalho As equações nos manuais escolares, traz uma reflexão subjacente à proposta deste artigo, uma vez que analisa livros didáticos - atores coadjuvantes nos processos de ensino e de aprendizagem de Matemática nas salas de aula. Ele investiga como a ideia de equação é tratada, do ponto de vista tanto conceitual como didático, em manuais escolares portugueses. Em seu trabalho, apresenta como a noção de equação é apresentada e discutida em quatro manuais portugueses - um do final do século XIX, outro de meados do século XX, outro da época da Matemática Moderna e outro da atualidade, nos anos 90. Nesses quatro manuais, o autor observa uma evolução muito significativa no ensino das equações, tanto do ponto de vista da idade do aluno com o qual se trabalha com essa noção matemática - que vai diminuindo dos 15 para os 12 anos -, como com relação à abordagem utilizada para discutila -, passando das abordagens mais formais e abstratas para aquelas mais simples e contextualizadas. Por fim, ressalta que, se, por um lado, essa evolução na apresentação do tema mostra transformações consideráveis no sentido de tornar esse conceito mais compreensível e atraente, por outro, a preocupação com a simplificação e a atratividade da mensagem pode ter levado a uma excessiva esquematização e à profusão de elementos decorativos. Ponte salienta, ao final do trabalho, a importância de observar mais profundamente a reflexão exposta acima, bem como de estudar se essa evolução ocorreu, e em que proporção, nos manuais de outros países.

As análises destes três trabalhos aqui discutidos - complementados pelo estudo das demais pesquisas que constituem a problemática aqui apontada parecem corroborar a principal questão que este artigo pretende discutir, quer seja: a abordagem de diferentes significados de equação como uma forma de contribuir com os alunos, com os professores, com o currículo - do ponto de vista do que se compreende por "conhecimento matemático para o ensino" (BALL; THAMES; PHELPS, 2008, p.395) 


\section{Conhecimento matemático para o ensino como o modelo teórico escolhido}

Nesta seção será apresentado e discutido o modelo teórico que irá fundamentar as análises desenvolvidas ao longo deste artigo. De fato, como anunciado inicialmente, o objetivo deste ensaio teórico é investigar as possíveis contribuições que a abordagem de diferentes significados do conceito de equação pode trazer para a constituição do conhecimento matemático para o ensino, no caso das equações.

Nesse sentido, optou-se por explorar o trabalho de Ball, Thames e Phelps (2008), em que os autores sistematizam diversos resultados de pesquisas, obtidos anteriormente pelo grupo liderado por Deborah Ball, na Universidade de Michigan. Nesse estudo, os autores desenvolvem - fundamentados na elaboração teórica de Shulman (1986) - a noção de Mathematical Knowledge for Teaching (MKT) - Conhecimento Matemático para o Ensino.

Segundo Ball, Thames e Phelps (2008), a introdução do termo conhecimento pedagógico do conteúdo (SHULMAN, 1986) sugere a necessidade de um conhecimento do conteúdo que é exclusivo para o ensino. Em continuidade aos seus estudos, ao apresentar a noção de conhecimento pedagógico do conteúdo, Shulman (1986) discute a ligação entre o conhecimento do conteúdo e a prática de ensino. Ball, Thames e Phelps (2008) contestam que, embora o termo conhecimento pedagógico do conteúdo esteja amplamente divulgado, seu potencial tem sido pouco explorado, pois muitos assumem que sua natureza e seu conteúdo são óbvios. Entretanto, o que se quer dizer por conhecimento pedagógico do conteúdo ainda é pouco especificado, sem uma definição e sem fundamentos empíricos, o que acaba por limitar a sua utilidade.

Na intenção de aprofundar e de ampliar o trabalho de Shulman (1986), Ball, Thames e Phelps (2008) apresentam dois projetos que focam o ensino de matemática e a matemática usada para o ensino. Os autores declaram que os dois estudos, acima citados, levaram-nos a construir novas hipóteses a respeito de refinamentos para o popular conceito de conhecimento pedagógico do conteúdo, e a ampliar o conceito de conhecimento do conteúdo para o ensino. Sendo assim, passam a focar a teorização da noção de conhecimento matemático para o ensino e as habilidades necessárias para os professores ensinarem. Com esse propósito, acabam por identificar e definir dois subdomínios do conhecimento pedagógico do conteúdo. Além disso, eles se surpreenderam, quando começaram a descobrir e a articular um domínio pouco reconhecido do conhecimento do 
conteúdo para o ensino que não está contido no conhecimento pedagógico do conteúdo, mas, segundo eles, é essencial para um ensino eficiente - o conhecimento especializado do conteúdo.

Fundamentadas nos resultados obtidos com os dois projetos desenvolvidos pelo grupo de Deborah Ball, as análises da prática dos professores revelaram que as demandas matemáticas para o ensino são consideráveis. O conhecimento matemático necessário para o ensino não é menor do que aquele de que outros adultos e outros profissionais necessitam. Para melhor contextualizar o que os autores querem dizer com isso, eles oferecem um exemplo baseado em uma simples conta de subtração:

Sem dúvida, apontam os autores, muitos leitores devem conhecer algum algoritmo para encontrar a resposta 139. Nesse projeto, Ball e seus colegas começam com uma tarefa puramente computacional, porque é uma situação na qual os professores, certamente, são capazes de desenvolver os cálculos por si próprios. O conhecimento matemático para executar esses cálculos é comumente conhecido por todos, pois é utilizado em vários contextos. Entretanto, ser capaz de realizar tais cálculos é necessário, mas não suficiente, para ensiná-lo.

Eles discutem que alunos, normalmente, cometem erros com o algoritmo da subtração. O professor deve ser capaz de perceber uma resposta incorreta. Entretanto, perceber o erro não é uma tarefa que exija algum conhecimento especial: qualquer um que pode resolver o problema anterior poderá verificar um resultado incorreto. Não obstante, ensinar envolve mais do que identificar uma resposta incorreta, pois requer capacidade de dimensionar a fonte do erro matemático. Em síntese, os professores precisam ser capazes de realizar análises eficientes e fluentes de erros matemáticos, uma prática comum entre os matemáticos no decorrer de seu próprio trabalho, por exemplo. Contudo, essa tarefa, no ensino, difere somente pelo fato de que o foco de análise são os erros produzidos por outros, pelos alunos.

Outro ponto importante, destacado pelos autores, refere-se à necessidade dos professores de reconhecer estratégias diferentes, não padronizadas, produzidas, muitas vezes, pelos alunos. Com frequência, estes se utilizam de estratégias pouco usuais e, nesse caso, o professor deve ser capaz de levantar questionamentos, como: É legítimo fazer isto?; Por quê?;Isto funciona, em geral?; Isto é mais fácil para algumas situações e mais difícil para outras?; Como descrever o método usado pelo aluno e como justificá-lo 
matematicamente?. Enfim, o professor precisa estar engajado com essa espécie de discurso interno da matemática, o qual é crucial para determinar o que fazer ao ensinar essa matemática.

Ainda nessa direção, destaca-se a importância de o professor confrontar diferentes formas de soluções apresentadas por alunos e de descobrir o que os alunos fizeram, se o pensamento utilizado está matematicamente correto e se a abordagem utilizada daria bom resultado em geral. Com isso, aponta-se que interpretar erros dos alunos e avaliar algoritmos alternativos apresentados por eles não é tudo o que o professor faz. Ensinar também envolve explicar procedimentos e apresentar justificativas plausíveis e válidas para tais procedimentos.

A partir dessas análises e reflexões, os autores enfatizam que seu ponto de vista não se limita ao que os professores precisam saber para ensinar, mas envolve, também, o que os professores, eles mesmos, precisam saber e ser capazes de fazer para realizar tal ensino. Nesse mesmo sentido, ressaltam a necessidade de os professores serem capazes de explicar o significado de conceitos e procedimentos (por exemplo, algoritmo da subtração e conceito de subtração) aos estudantes e de escolher exemplos e situações que sejam adequados para tal desenvolvimento. Toda essa discussão aponta a relevância de um tipo de raciocínio matemático crucial para o ensino, mas ainda estranho à maioria dos adultos, embora estes tenham recebido uma boa educação. Isto é o que eles chamam de demandas matemáticas especiais para o ensino de matemática. A partir dos resultados da pesquisa,

[...] eles começaram a notar o quão raramente essas demandas matemáticas poderiam ser resolvidas com o conhecimento matemático aprendido em cursos universitários de matemática. Eles começaram a conjecturar que existem aspectos do conhecimento do conteúdo - além do conhecimento pedagógico do conteúdo - que precisam ser descobertos, mapeados, organizados e incluídos nos cursos de matemática para professores. (BALL; THAMES; PHELPS, 2008, p. 398).

Com isso, Ball, Thames e Phelps (2008) conjeturam que (1) o conhecimento do conteúdo (SHULMAN, 1986) poderia ser subdividido em CCK ${ }^{1}$ (conhecimento comum do conteúdo) e $\mathrm{SCK}^{2}$ (conhecimento especializado do conteúdo); (2) o conhecimento pedagógico do conteúdo (SHULMAN, 1986)

\footnotetext{
${ }^{1}$ Common Content Knowledge
}

${ }^{2}$ Specialized Content Knowledge 
poderia ser subdividido em $\mathrm{KCS}^{3}$ (conhecimento do conteúdo e de estudantes) e $\mathrm{KCT}^{4}$ (conhecimento do conteúdo e de ensino).

Em síntese, eles definem: reconhecer uma resposta errada é um conhecimento comum do conteúdo (CCK); dimensionar rapidamente a natureza de um erro, especialmente aqueles que não são familiares, é um conhecimento especializado do conteúdo (SCK); ter familiaridade com os erros comuns e saber por que diversos alunos os cometem é um conhecimento de conteúdo e de estudantes (KCS); selecionar uma abordagem de ensino que seja eficiente para superar certas dificuldades e/ou explorar certos aspectos de um conteúdo é um conhecimento do conteúdo e de seu ensino (KCT). Ball, Thames e Phelps (2008) chamam atenção para a alocação provisória da terceira categoria de Shulman (1986), conhecimento curricular, dentro do conhecimento pedagógico do conteúdo. O esquema abaixo ilustra a constituição original proposta por eles:

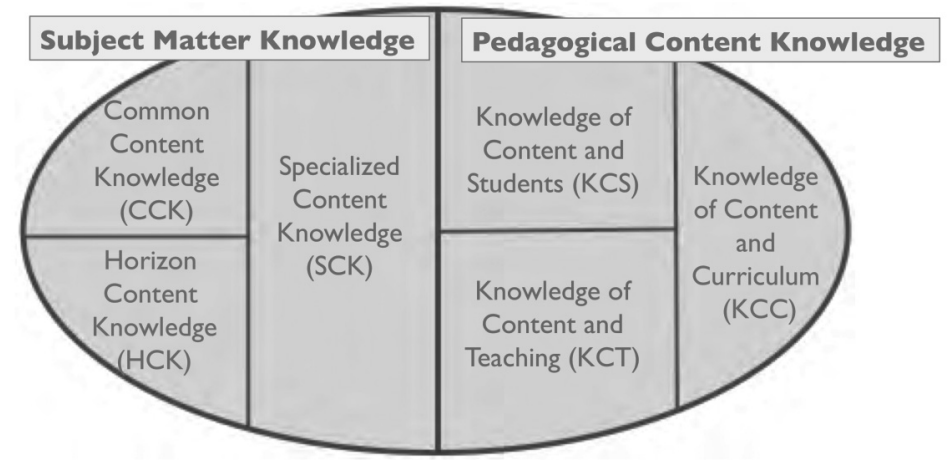

Figura 1 - Domínios do conhecimento matemático para o ensino Fonte: adaptado da figura apresentada em Ball, Thames e Phelps (2008, p. 403)

Finalizando, é importante apresentar, aqui, as conclusões dos autores, e aproximar tais conclusões dos objetivos do presente artigo: (1) professores precisam saber/conhecer o assunto (conteúdo) que ensinam, por uma simples razão: professores que não conhecem bem um assunto provavelmente não terão o conhecimento necessário de que precisam para ajudar estudantes a aprendêlo. Entretanto, conhecer bem um assunto não é suficiente para ensiná-lo; (2) os cursos de formação de professores não devem focar somente os ganhos de aprendizagem matemática de seus alunos, mas parece mais importante que

\footnotetext{
${ }^{3}$ Knowledge of Content and Students

${ }^{4}$ Knowledge of Content and Teaching
} 
preparem os professores para conhecerem e ser capazes de usar a matemática que é necessária no trabalho de ensinar.

\section{Diferentes significados de equação: explorando alguns resultados de pesquisas}

Investigar as possíveis contribuições que a abordagem de diferentes significados do conceito de equação pode trazer para a constituição do conhecimento matemático para o ensino, no caso das equações, é o que se pretende alcançar ao longo deste trabalho. Na seção anterior, dissertou-se sobre tal modelo teórico, na expectativa de preparar o leitor para as análises e as reflexões que serão desenvolvidas a seguir. Inicialmente, serão apresentados os resultados de pesquisas que contemplam diferentes significados do conceito de equação (RIBEIRO, 2007; BARBOSA, 2009; DORIGO, 2010; STEMPNIAK, 2011). Em seguida, passar-se-á a dissertar acerca das possíveis relações entre tais significados e o conhecimento matemático para o ensino.

Os diferentes significados do conceito de equação que serão discutidos são frutos dos trabalhos de Ribeiro (2007), de Barbosa (2009), de Dorigo (2010) e de Stempniak (2011). Trata-se de quatro trabalhos de naturezas diversas, porém complementares. Ribeiro (2007) desenvolveu um trabalho de caráter teórico, no qual identificou diferentes significados do conceito de equação por meio de estudos epistemológico e didático. Em continuidade a esses estudos, Barbosa (2009) e Dorigo (2010) propuseram-se, em suas pesquisas, a investigar se e como os significados identificados na pesquisa de Ribeiro estão presentes nas concepções de professores e alunos, respectivamente. O trabalho de Stempniak (2010) investigou quais significados de equação emergem, ou são possíveis de contemplar, em um ambiente de modelagem matemática, com alunos de um curso de licenciatura em matemática.

Em Ribeiro (2007), o conjunto dos diferentes significados identificados - nomeados por ele Multisignificados de Equação - compreende diferentes formas de ver, de interpretar e de tratar o conceito de equação. A problemática de seu trabalho foi desenvolvida a partir da análise de referenciais bibliográficos de naturezas diversas - livros didáticos, livros de fundamentos da Matemática, dicionários matemáticos e etimológicos, além de relatórios de pesquisas em Educação Matemática. Tais análises revelaram diferentes formas pelas quais diferentes povos, em diferentes épocas históricas, entendiam e utilizavam o conceito de equação. Em síntese, ao concluir sua pesquisa - que foi desenvolvida 
na perspectiva de um ensaio teórico - Ribeiro (2007) categorizou e classificou os significados de equação por ele identificados em: intuitivo-pragmático; dedutivo-geométrico; estrutural-generalista; estrutural-conjuntista; processual-tecnicista; axiomático-postulacional. O Quadro 1 traz tais significados e suas caracterizações:

\begin{tabular}{|c|c|}
\hline Significado & Características \\
\hline Intuitivo-Pragmático & $\begin{array}{l}\text { Equação concebida como noção intuitiva, ligada à ideia de } \\
\text { igualdade entre duas quantidades. Utilização relacionada à } \\
\text { resolução de problemas de ordem prática, originários de } \\
\text { situações do dia a dia. }\end{array}$ \\
\hline Dedutivo-Geométrico & $\begin{array}{l}\text { Equação concebida como noção ligada a figuras geométricas, } \\
\text { segmentos e curvas. Utilização relacionada a situações } \\
\text { envolvendo cálculos e operações com segmentos, com medida } \\
\text { de lados de figuras geométricas e interseç̧ão de curvas. }\end{array}$ \\
\hline Estrutural-Generalista & $\begin{array}{l}\text { Equação concebida como noção estrutural definida e com } \\
\text { propriedades e características próprias, considerada por si } \\
\text { própria e operando-se sobre ela. Utilização relacionada com a } \\
\text { busca de soluções gerais para uma classe de equações de mesma } \\
\text { natureza. }\end{array}$ \\
\hline Estrutural-Conjuntista & $\begin{array}{l}\text { Equação concebida dentro de uma visão estrutural, porém } \\
\text { diretamente ligada à noção de conjunto. É vista como uma } \\
\text { ferramenta para resolver problemas que envolvam relações entre } \\
\text { conjuntos. }\end{array}$ \\
\hline Processual-Tecnicista & $\begin{array}{l}\text { Equação concebida como a sua própria resolução - os métodos } \\
\text { e as técnicas que são utilizadas para resolvê-la. Diferentemente } \\
\text { do significado estruturalista, a equação aqui não é vista como } \\
\text { um ente matemático. }\end{array}$ \\
\hline Axiomático-Postulacional & $\begin{array}{l}\text { Equação concebida como noção da Matemática que não precisa } \\
\text { ser definida, uma ideia a partir da qual outras ideias, } \\
\text { matemáticas e não matemáticas, são construídas. Utilizada no } \\
\text { sentido de noção primitiva, como ponto, reta e plano na } \\
\text { Geometria Euclidiana. }\end{array}$ \\
\hline
\end{tabular}

Quadro 1 - Significados de equação e suas características

Fonte: adaptado a partir da tabela apresentada em Ribeiro (2007, p. 127-128)

Como apontado anteriormente, as pesquisas de Barbosa (2009), de Dorigo (2010) e de Stempniak (2011) surgiram com o propósito de dar continuidade aos trabalhos iniciados por Ribeiro. As duas primeiras, embora tenham tido professores e alunos como fonte de dados, caracterizaram-se como pesquisas diagnósticas, ou seja, não houve nenhum tipo de intervenção nos processos de ensino e de aprendizagem de equações envolvendo tais atores. Por outro lado, a pesquisa de Stempniak desenvolveu-se na perspectiva de uma pesquisa experimental com um grupo de alunos do último ano da licenciatura em matemática. Os dados dessas três pesquisas - que serão discutidos a seguir -, adicionados aos resultados da pesquisa de Ribeiro, constituirão a fonte de dados que serão analisados sob a 
ótica da elaboração teórica do Conhecimento Matemático para o Ensino.

Considerando-se as similaridades das pesquisas de Barbosa (2009) e de Dorigo (2010), apresentam-se, a seguir, algumas das análises feitas em seus trabalhos e que serão posteriormente retomadas, num diálogo que se pretende constituir com as demais pesquisas aqui consideradas. Como enunciado anteriormente, as pesquisas de Barbosa (2009) e de Dorigo (2010) tiveram por objetivo identificar se e como os diferentes significados categorizados por Ribeiro (2007) se manifestavam nas concepções de professores de matemática e de alunos do ensino médio, respectivamente. Para tal, foram elaboradas situações matemáticas específicas para a coleta de dados. No trabalho de Barbosa (2009), os professores foram entrevistados pelo pesquisador, seguindo um roteiro fundamentado em tais situações matemáticas. Já em Dorigo (2010), os dados foram coletados com os alunos trabalhando em pequenos grupos e respondendo a um questionário que contemplava as situações matemáticas que foram elaboradas.

Em ambas as pesquisas, identificou-se uma forte incidência do significado Intuitivo-Pragmático, tanto nas concepções de professores como nas dos alunos. Entretanto, aparece com mais naturalidade nos resultados de Dorigo (2010) a utilização de tal significado, ainda que os alunos tivessem sentido uma grande necessidade de utilizar-se de procedimentos e técnicas (significado ProcessualTecnicista) para tratar as situações às quais foram expostos. Por outro lado, na pesquisa de Barbosa (2009), a presença do significado Processual-Tecnicista é mais aparente e frequente, se comparada com a pesquisa de Dorigo. Segundo Barbosa (2009), os professores investigados encontraram dificuldades para tratar as situações matemáticas em que se envolveram, quando não se recordavam de uma fórmula e/ou de um algoritmo de resolução. Embora tais professores também utilizassem o significado Intuitivo-Pragmático, pareciam não se sentir tão à vontade como os alunos para usar estratégias aritméticas.

No intuito de ilustrar e fundamentar as discussões acima contempladas apresenta-se, a seguir, um exemplo de situação matemática utilizada nas pesquisas desses autores. A situação matemática escolhida é relacionada ao significado Intuitivo-Pragmático e foi contemplada nas duas pesquisas, ou seja, foi vivenciada tanto por professores como por alunos.

SITUAÇÃO 1: situação matemática que remete ao significado Intuitivo-Pragmático, uma vez que a equação emerge de uma situação do cotidiano (pragmático) e pode ser tratada numericamente, utilizando-se de conhecimentos já adquiridos pelos indivíduos (intuitivo). 
Uma aluna, Bianca, fã de música, reserva num certo mês $\mathrm{R} \$ 70,00$ para a compra de CDs ou DVDs. Um CD custa $R \$ 12,00$ e um DVD custa $R \$ 16,00$. Quais as possibilidades de compra desses dois bens, gastando exatamente os $\mathrm{R} \$ 70,00$ ?

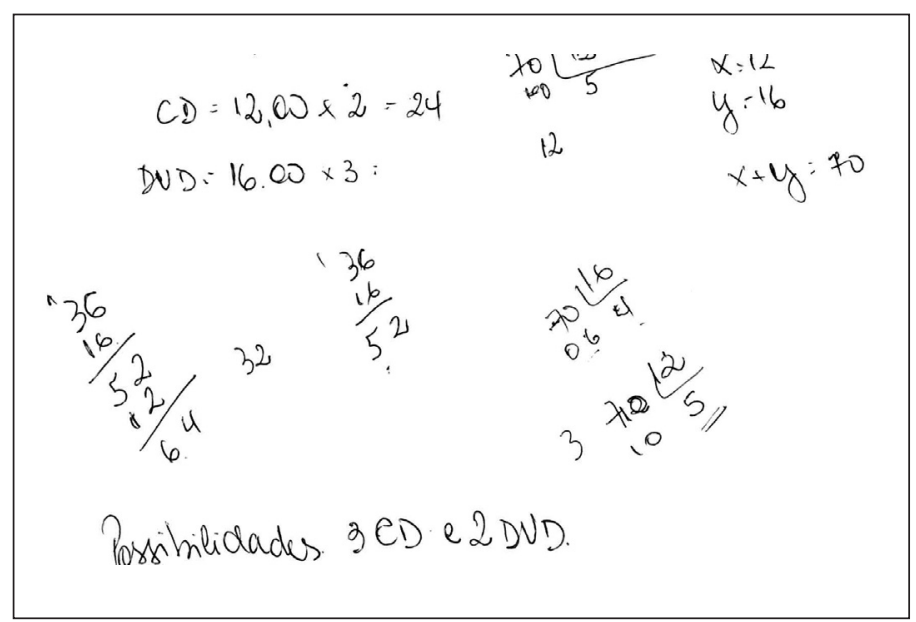

\section{Protocolo Professor A}

B. Por tentativa assim eu não consegui achar qual seria as possibilidades, sem usar fórmula nenhuma, tentando assim, por tentativa, colocando, comprando dois DVDs, um $\mathrm{CD}$, não sei o quê... ou então usando...

\section{Transcrição Professor B}

\section{$12 x+16 y=70$}

Protocolo Professor C

C. Se eu atribuir valores para x e para y, se não, não dá, ou se eu tivesse outra equação montar um sistema.

\section{Transcrição Professor C}




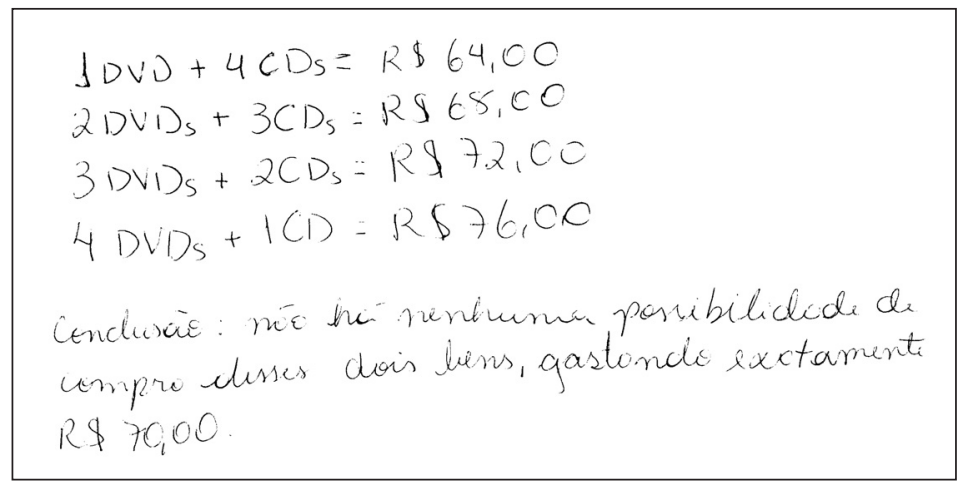

Protocolo Alunos (Dupla 1)

Transcrição 1- Não reconhecemos e nem utilizamos equação. Pensamos que a melhor forma seria, ou a única forma que sabíamos de resolver era "chutando" para encontrar o resultado.

\section{Transcrição alunos-Dupla 1}

Em Stempniak (2010), a pesquisadora desenvolveu um estudo experimental, como já apontado neste texto, no qual investiga - num ambiente de modelagem matemática - quais significados de equação emergem e/ou são possíveis contemplar com alunos do último ano de um curso de licenciatura em matemática. Para tal, foram elaboradas três situações-problema que poderiam propiciar o surgimento de diferentes significados do conceito de equação ao longo do desenvolvimento e do debate promovido no ambiente da pesquisa. Stempniak coletou seus dados, trabalhando com os alunos em pequenos grupos, bem como em momentos de discussões coletivas de toda a turma de participantes.

Em suas análises pôde constatar que (1) num primeiro momento os alunos lançaram mão do significado intuitivo-pragmático - assim como identificado em Barbosa (2009); (2) ao longo das discussões nos pequenos grupos e/ou no debate gerado na sala de aula, outros significados, como o estruturalgeneralista e/ou o estrutural-conjuntista, foram contemplados pelos alunos. Por outro lado, cabe ressaltar que a segunda atividade proposta por ela - a qual poderia propiciar o surgimento e/ou o desenvolvimento do significado dedutivogeométrico, por tratar-se de uma situação-problema que envolvia conhecimentos geométricos - não alcançou tal objetivo.

Dentre as três atividades propostas pela pesquisadora, escolheu-se, para 
ilustrar os principais resultados obtidos, a terceira atividade, a qual contemplava uma situação-problema envolvendo equações e funções exponenciais e logarítmicas e poderia propiciar o trabalho com diferentes significados concomitantemente.

Atividade 3: Pouco mais de 11 milhões de pessoas vivem em São Paulo, mas a população que mais cresce na cidade não é a humana. Enquanto o número de homens, entre 2002 e 2008, cresceu 3,5\%, a quantidade de cães aumentou 60\%, de acordo com estudo da Faculdade de Medicina Veterinária e Zootecnia da Universidade de São Paulo (USP).

$O$ último censo animal, realizado em 2002 pelo Centro de Controle de Zoonoses (CCZ), indicava 1,5 milhão de cães na capital. Em 2008, a população canina alcançou 2,4 milhões. Estima-se que, para cada 4,5 moradores da cidade, exista um cão.

Segundo estudos realizados pela Faculdade de Medicina Veterinária e Zootecnia da USP, que compõem o chamado censo animal, mantidas as taxas de crescimento atuais, o número de cães poderá superar o número de habitantes da cidade de São Paulo. Seremos 12,482 milhões de pessoas, contra pouco mais de 13 milhões de cães na cidade. Em que ano isso irá acontecer?

A2: Este é aquele que dá para usar logaritmo um número elevado a seis...

A1: Não, este não é logaritmo, não. Esse dá para usar proporção direto, quer ver? Deixa eu fazer...

\section{Transcrição 14}

P: Que tipo de conteúdo da matemática vocês pensaram para resolver esta atividade? A: Proporção, porcentagem, estimativa.

A: Nós pensamos assim: se, em cada ano, está aumentando 10\% mais ou menos, pois, se em seis anos foram $60 \%$, então em cada ano foram $10 \%$...

$\mathrm{P}:$ Mas se é um crescimento de populações, é assim que se calcula?

A: Tem que usar os dados da atividade para encontrar uma taxa de crescimento.

A: Matematicamente falando, nós temos que ter um valor vamos supor que neste ano cresça mais que o ano que vem. Mesmo assim, matematicamente falando, temos que ter uma proporção, uma taxa do crescimento.

\section{Transcrição 15}




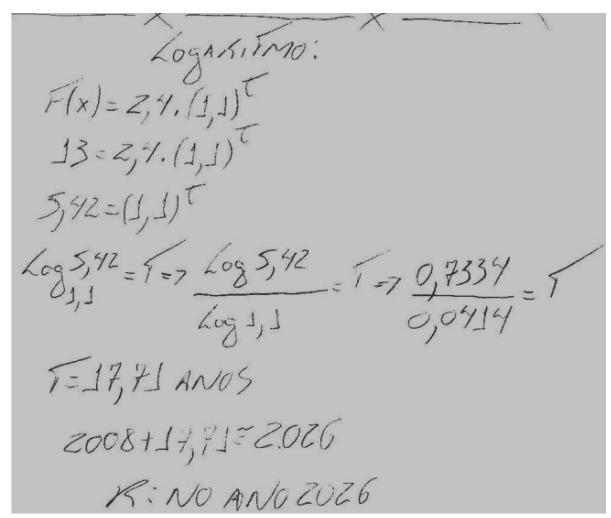

Protocolo 14

A1: Vamos usar logaritmo, em função do tempo...

A3: Queremos saber em que ano 13 milhões de cachorros habitará a cidade de São Paulo, então faremos 2,4 milhões, que foi em 2008; e, depois, a taxa de 10\% mais ou menos, então é $100 \%$ mais 10\%, que dá 1,1 em função do tempo ..."

\section{Transcrição 16}

A: Podemos usar uma exponencial, pois fala de taxa de crescimento, isso é uma equação exponencial, mas o problema que o crescimento não é linear aí não tem como fazer...

\section{Transcrição 17}

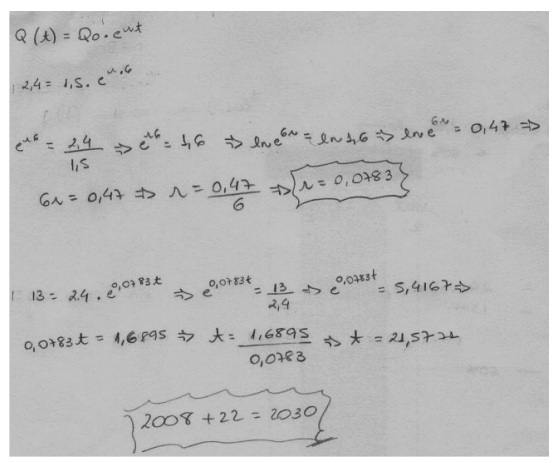

\section{Protocolo 16}

As análises da atividade acima, desenvolvidas pela pesquisadora, parecem ratificar, de certa forma, a emergente necessidade de trazer para o âmbito da formação do professor de matemática a abordagem de conceitos matemáticos da Educação Básica numa perspectiva distinta da simples revisão 
de conteúdos:

É fato que, no caso de nossa pesquisa, o ambiente de Modelagem Matemática utilizado durante o desenvolvimento das atividades proporcionou aos alunos a possibilidade de discussões entre os trios e com o pesquisador. Em nosso entendimento, tal ambiente possibilitou uma ampliação do conhecimento específico do conteúdo, a equação, pois as discussões auxiliaram os alunos em suas resoluções. Um bom exemplo disso foi a atividade 3 , em que usamos a equação de $\ln$ - que os alunos até então desconheciam - para a resolução da atividade. (STEMPNIAK, 2011, p. 102).

Tal reflexão pode ser corroborada pelo protocolo abaixo, que transcreve as considerações de um dos alunos por ela pesquisados:

A1: Olha, eu acho interessante isso, o problema te dá uma média, fala que 2002 a 2008 o crescimento é de 60\%, e isso te dá algo a pensar em algo linear, que dá a entender que é uma função do primeiro grau. Se você for seguir o que está escrito no problema, você segue a ideia de algo linear...

... Estamos acostumados a somente utilizar resoluções de problemas e não paramos para refletir ou discutir o que os problemas estão relatando... Só fui enxergar a utilização de um logaritmo ou uma exponencial depois de ter analisado e discutido a situação ... Se não houvesse essas discussões eu teria feito somente por algo linear... Muito interessante esse jeito da Modelagem Matemática... nunca tinha visto... Ela te dá outra visão, te leva a refletir, a pensar de como utilizar a matemática para resolver problemas... que às vezes parece ser de um jeito, mas vemos, com as discussões, que poder ser feito de outro jeito.

\section{Transcrição 18}

Na próxima e última seção do presente trabalho, pretende-se apresentar as relações identificadas entre os diferentes significados de equação - ora discutidos - e a noção de conhecimento matemático para o ensino, bem como dissertar acerca das potencialidades de uma abordagem de ensino fundamentada nos diferentes significados de equação.

\section{Reflexões finais: equação e conhecimento matemático para o ensino - relações e potencialidades}

A proposta do presente trabalho - desenvolvido na perspectiva de um ensaio teórico - foi tecer relações e apontar potencialidades para a constituição 
do que Ball e seus colegas denominam Conhecimento Matemático para o Ensino, em particular, para o conceito de equação. No intuito de alcançar tal objetivo, constituiu-se uma problemática acerca do ensino e da aprendizagem de Álgebra, com ênfase em pesquisas sobre equações. Em continuidade, discorreu-se sobre a elaboração teórica de Ball, Thames e Phelps (2008), apontando suas ideias centrais e que fundamentam esse ensaio, no que se refere ao Conhecimento Matemático para o Ensino. Considerando a centralidade que os diferentes significados de equação têm no presente trabalho, discutiram-se, na seção anterior, pesquisas que contemplam essa temática. Agora, por fim, passa-se às análises desses diferentes significados à luz do modelo teórico eleito.

De acordo com Ball, Thames e Phelps (2008), o Conhecimento Matemático para o Ensino (Mathematical Knowledge for Teaching - MKT no original) é composto por um amálgama de subdomínios do conhecimento específico e do conhecimento didático de um conteúdo, o qual pode ser sintetizado na Figura 2:

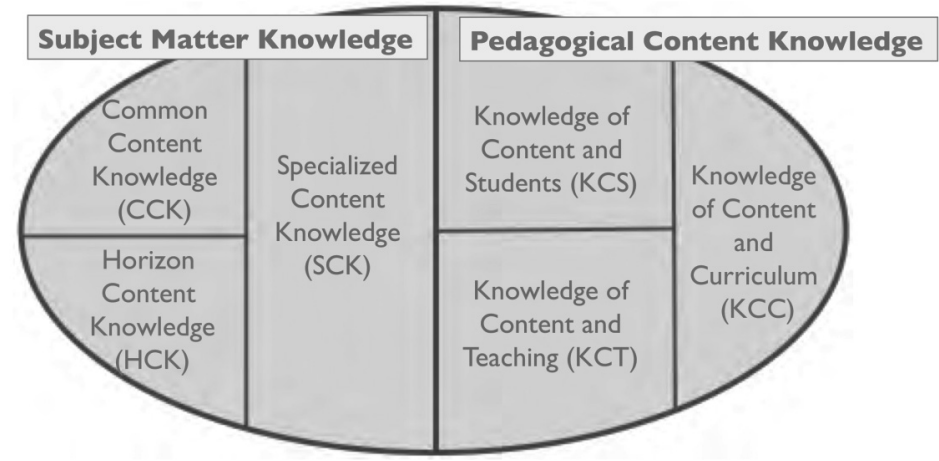

Figura 2 - Domínios do conhecimento matemático para o ensino

Fonte: adaptado da figura apresentada em Ball, Thames e Phelps (2008, p. 403)

Nesse modelo, o conhecimento específico do conteúdo foi subdividido em conhecimento especializado e conhecimento comum do conteúdo. Num outro lado, foram identificados - como subdomínios do conhecimento pedagógico do conteúdo - o conhecimento do conteúdo e dos estudantes e o conhecimento do conteúdo e do seu ensino.

Considerando o objetivo do presente trabalho, as discussões dos resultados das pesquisas acerca dos diferentes significados de equação (RIBEIRO, 2007; BARBOSA, 2009; DORIGO, 2010; STEMPNIAK, 2011) parecem indicar algumas relações entre tais significados e o MKT. Em Ribeiro (2007), o estudo 
epistemológico que resultou na categorização de seis significados indica um caminho para contemplar um tipo de conhecimento especializado do conteúdo útil e importante - para o professor de matemática exercer, de maneira eficaz, seu papel no ensino. Ao abordar o conceito de equação, na perspectiva que o referido estudo faz, passa-se a colocar foco em discussões acerca (1) de um conteúdo relevante da álgebra; (2) de questões estruturais da álgebra; (3) do papel e do lugar da álgebra dentro da matemática; (4) da natureza de valiosas atividades de álgebra para os aprendizes; (5) das conexões entre álgebra e outras áreas da matemática e fenômenos físicos (ARTIGUE et al., 2001).

Em Barbosa (2009), por sua vez, os resultados e as conclusões advindas de seu estudo parecem indicar a predominância de um conhecimento comum do conteúdo, uma vez que os professores por ele investigados lançaram mão, frequentemente, do significado processual-tecnicista ao longo das entrevistas:

Percebemos em nossa pesquisa que a presença de diferentes significados de equação na imagem de conceito dos professores ainda é bastante limitada, estando muito vinculada à ideia do princípio de equivalência e principalmente a técnicas de resolução e à existência de incógnita. (BARBOSA, 2009, p. 177).

O trabalho que Dorigo (2010) desenvolveu com alunos do ensino médio, investigando se e quais significados de equação estão presentes em suas concepções, pode oferecer, a partir de seus resultados, contribuições para a identificação e para o levantamento do que Ball e seus colegas chamam de conhecimento do conteúdo e dos estudantes. Ao identificar quais significados são mais frequentes nas concepções dos alunos investigados, bem como ao tentar compreender o que esses alunos entendem por equação, Dorigo concluiu: [...] que o significado intuitivo-pragmático e o significado processual-tecnicista foram os encontrados em algumas das situações desenvolvidas por esse grupo de alunos; e que o reconhecimento de uma equação não está claro para eles. (DORIGO, 2010, p. 120).

Além disso, em sua pesquisa Dorigo deixa aos professores de matemática uma recomendação que ratifica a premissa, acima apontada, relativa ao conhecimento do conteúdo e dos estudantes, nesse caso, no que se refere ao conceito de equação: 
Dessa forma, gostaríamos de deixar como sugestão, para professores de Matemática, que trabalhem outros significados com seus alunos, o que pode possibilitar um repertório e um instrumental mais amplo para estes, principalmente quando estiverem envolvidos com a resolução de problemas que contemplem tal ideia matemática. (DORIGO, 2010, p. 120).

A pesquisa de Stempniak (2011), ao discutir diferentes significados de equação com alunos do último ano de licenciatura, parece encorpar as relações até aqui identificadas. Em seu trabalho, ao propiciar que os futuros professores vivenciassem situações-problema envolvendo diferentes significados e diferentes tipos de equação, identificam-se relações entre os resultados de sua pesquisa e os dos subdomínios indicados por Ball e seus colegas - o conhecimento especializado do conteúdo e o conhecimento do conteúdo e de seu ensino. Nas transcrições e nos protocolos, ora apresentados, observa-se que esses futuros professores aprofundaram e especializaram seus conhecimentos acerca das equações logarítmicas, por exemplo, além de vivenciarem situações de ensino que podem utilizar futuramente, ao ensinar matemática:

Muitas vezes, o conhecimento específico do conteúdo "equação" e os significados de equação não apareceram logo nas primeiras soluções dos alunos: isso só ocorreu depois das discussões que fazíamos entre os trios; ou surgiam em algumas atividades, como no item d) da atividade 1, em que, só depois de termos discutido, é que os alunos conseguiram identificar as funções; e foram surgindo os significados estrutural-conjuntista, estrutural-generalista e intuitivo-pragmático. (STEMPNIAK, 2011, p. 103).

Fundamentado nessas análises, apresenta-se um esboço preliminar, contemplando as relações entre as pesquisas que discutem diferentes significados de equação e o modelo teórico - conhecimento matemático para o ensino - no âmbito do conceito de equação. Identificou-se a possibilidade de explorar o subdomínio conhecimento especializado do conteúdo, a partir dos resultados de Ribeiro (2007); a necessidade de ampliar o subdomínio conhecimento comum do conteúdo, identificado em Barbosa (2009); as implicações dos resultados de Dorigo (2010) para o conhecimento do conteúdo e dos estudantes; as possibilidades de exploração do conhecimento especializado do conteúdo e do conhecimento do conteúdo e de seu ensino, a partir das análises feitas em 
Stempniak (2011). Na Figura 3, procura-se sintetizar as relações identificadas entre os diferentes significados de equação, contemplados nas pesquisas anteriores, e o conhecimento matemático para o ensino:

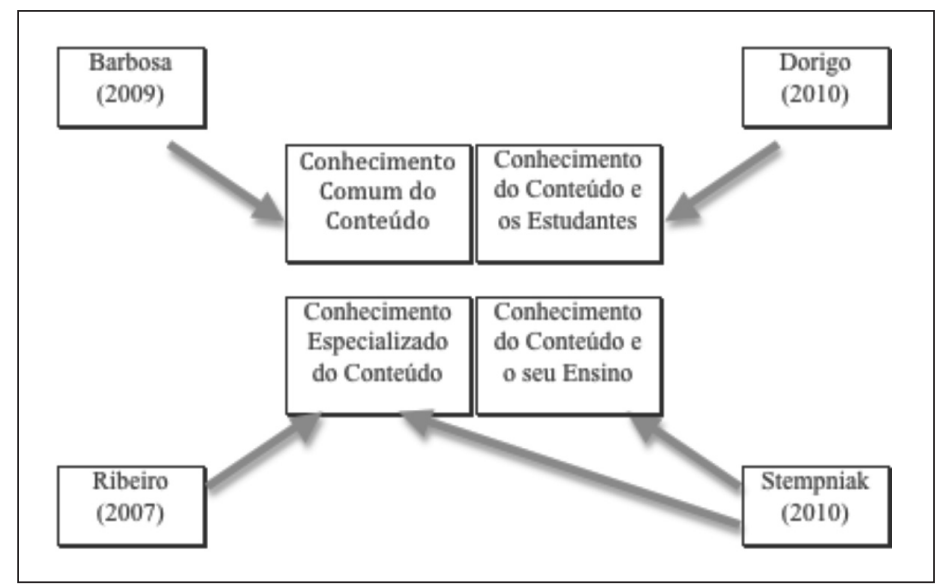

Figura 3 - Esquema relacionando diferentes significados de equação e o modelo de Ball, Thames e Phelps (2008)

Considerando esse contexto, finaliza-se o presente ensaio teórico, procurando apontar potencialidades que uma abordagem de ensino fundamentada nos diferentes significados de equação e no modelo teórico do conhecimento matemático para o ensino pode trazer para formação do professor de matemática.

Aparentemente, uma proposta baseada nessas premissas parece contemplar exclusivamente o conhecimento teórico, em detrimento da prática do professor. Entretanto, vale lembrar que a metodologia utilizada por Ball e seus colegas para o levantamento e a identificação do que eles chamam de conhecimento matemático para o ensino prioriza, justamente, a prática do professor em salas de aula. As pesquisas desenvolvidas pelo grupo sempre partem da observação dos professores em ação, para, então, juntamente com eles, delinear um "conhecimento matemático necessário para realizar o trabalho de ensinar matemática” (BALL; THAMES; PHELPS, 2008, p. 395).

Assim sendo, conjeturam-se, nestas reflexões finais, as potencialidades do trabalho com diferentes significados de equação no âmbito da formação do professor de matemática. Se, por um lado, pode-se explorar o conhecimento do professor sobre álgebra - enfatizando uma dimensão epistemológica (ARTIGUE et al., 2001), como apontado anteriormente -, também é possível, e desejável, 
que se contemplem as dimensões cognitiva e didático-pedagógica do conhecimento do professor para ensinar.

Segundo Artigue et al. (2001), a dimensão cognitiva inclui, entre outras, conhecer (1) o desenvolvimento do pensamento algébrico dos estudantes; (2) as suas interpretações sobre conceitos e notação algébrica; (3) as suas dificuldades em álgebra, incluindo os obstáculos epistemológicos e didáticos; (4) as diferentes abordagens utilizadas pelos estudantes. Entende-se que a abordagem dos diferentes significados de equação, na perspectiva do conhecimento matemático para o ensino, parece contemplar ou favorecer a exploração dessa dimensão nas aulas de matemática. O trabalho de Dorigo (2010) e o de Stempniak (2010) ilustram tais reflexões, na medida em que procuram compreender o que pensam os alunos a respeito do conceito de equação e o que fazem esses alunos, quando estão envolvidos com situações-problema que contemplam o conceito de equação.

Ainda, reportando a Artigue et al. (2001), a dimensão didático/pedagógica inclui, entre outras, conhecer (1) o currículo; (2) as fontes (materiais curriculares); (3) as diferentes representações instrucionais; (4) as diferentes práticas assumidas por outros professores; (5) a natureza e o desenvolvimento de um discurso eficaz nas salas de aula. Novamente, é possível observar preocupações nessa direção nos trabalhos de Barbosa (2009) e de Stempniak (2011), uma vez que ambos investigam - ainda que de forma adjacente - a prática do professor de matemática e, principalmente a segunda autora, o papel das discussões entre os alunos e com a pesquisadora para a constituição dos conhecimentos daqueles enquanto professores em formação.

Certamente, há muito o quê investigar e estudar em relação ao conhecimento matemático para o ensino, ainda que se considere somente o conceito de equação. A proposta tomada para esse artigo foi de apresentar alguns resultados preliminares de uma agenda de pesquisa que se abre e parece ser de extrema relevância para a formação do professor de matemática, em particular para o professor que ensina álgebra. Doerr (2004) pontua, de forma muito pertinente e fundamentada, a urgência por estudos e por teorias que possam identificar, compreender e explicar o conhecimento do professor e o ensino de álgebra. 


\section{Referências}

ALMEIDA, M. M. M. Estratégias de generalização de padrões de alunos do Ensino Fundamental do ponto de vista de seus professores. 2006, 97f. Dissertação (Mestrado em Educação Matemática) - Pontifícia Universidade Católica de São Paulo, São Paulo, 2006.

ARTIGUE, M.; ASSUDE, T.; GRUGEON, B; LENFANT, A. Teaching and learning algebra: approaching complexity through complementary perspectives. In: ICMI STUDY CONFERENCE, $12^{\text {th }}, 2001$, Melbourne, Austrália. Proceedings ... Melbourne: The University of Melbourne. 2001, p. 21 - 32. CHICK, H.; STACEY, K.; VINCENT, J.; VINCENT, J. (Ed.).

ATTORPS, I. Teachers' images of the 'equation' concept. European Research in Mathematics Education, v. 3, 2003. Disponível em: <http://ermeweb.free.fr/cerme3/ groups/tg1/ tg1_list_html>. Acesso em: 15 dez. 2006.

BALL, D. L.; THAMES, M. H.; PHELPS, G. Content knowledge for teaching: What makes it special? Journal of Teacher Education, New York, v. 59, n. 5, p. 389 - 407, nov./dez. 2008.

BARBOSA, Y. O. Multisignificados de equação: uma investigação sobre as concepções de professores de Matemática. 2009, 196f. Dissertação (Mestrado em Educação Matemática) - Universidade Bandeirante de São Paulo, São Paulo, 2009.

COTRET, R. S. Problématique à propos de la mise en équation de problèmes écrits. In: SÉMINAIRE FRANCO-ITALIEN DE DIDACTIQUE DE L'ALGÈBRE, 9., 1997, Nice. Anais... Nice: SFIDA, 1997, p. 23 - 37.

DOERR, H. M. Teachers' Knowledge and Teaching of Algebra. In : STANCEY, K.; CHICK, H.; KENDAL, M. (Eds.) The future of the teaching and learning of algebra: The 12th ICMI Study. New York : Kluwer Academic Publishers, 2004. p. 267 - 289.

DORIGO, M. Investigando as concepções de equação de um grupo de alunos do Ensino Médio. 2010, 137f. Dissertação (Mestrado em Educação Matemática) Universidade Bandeirante de São Paulo, São Paulo, 2010.

FIGUEIREDO, A. Saberes e concepções de educação algébrica em um curso de Licenciatura em Matemática. 2007, 290 f. Tese (Doutorado em Educação Matemática) - Pontifícia Universidade Católica de São Paulo, São Paulo, 2007. 
KILPATRIC, J.; IZSÁK, A. A history of Algebra in the school curriculum. In: GREENES, C. E.; RUBENSTEIN, R. (Eds.). Algebra and algebraic thinking in school Mathematics. 70th Yearbook of the National Council of Teachers of Mathematics. Reston: NCTM, 2008. p. 3 - 18.

\section{LI, X. An investigation of secondary school Algebra teachers' mathematical} knowledge for teaching algebraic equation solving. 2007, 318f. Tese (Doutorado em Educação Matemática) - The University of Texas at Austin, Austin, 2007.

LIMA, R. N. Equações algébricas no Ensino Médio: uma jornada por diferentes mundos da Matemática. 2007, 358f. Tese (Doutorado em Educação Matemática) Pontifícia Universidade Católica de São Paulo, São Paulo, 2007.

PONTE, J. P. da. As equações nos manuais escolares. Revista Brasileira de História da Matemática, Rio Claro, v. 4, n. 8, p. 149 - 170, 2004.

RIBEIRO, A. J. Analisando o desempenho de alunos do Ensino Fundamental em Álgebra, com base em dados do SARESP. 2001. 116f. Dissertação (Mestrado em Educação Matemática) - Pontifícia Universidade Católica de São Paulo, São Paulo, 2001.

RIBEIRO, A. J. Equação e seus multisignificados no ensino de Matemática: contribuições de um estudo epistemológico. 2007, 142f. Tese (Doutorado em Educação Matemática) - Pontifícia Universidade Católica de São Paulo, São Paulo, 2007.

RIBEIRO, A. J.; MACHADO, S. D. A. Equação e seus multisignificados: potencialidades para a construção do conhecimento matemático. Zetetiké, Campinas, v. 17, n. 31, p. 109 - 128, jan./jun. 2009.

SHULMAN, L. S. Those who understand: Knowledge growth in the teaching. Educational Researcher,Washington, US, v. 15, n. 2, p. 4 - 14, 1986.

STEMPNIAK, I. G. B. Multisignificados de equação e o professor de Matemática: um estudo sobre a Modelagem Matemática num curso de licenciatura. 2010, $121 \mathrm{f}$. Dissertação (Mestrado em Educação Matemática) - Universidade Bandeirante de São Paulo, São Paulo, 2011.

Submetido em Abril de 2011. Aprovado em Junho de 2011. 

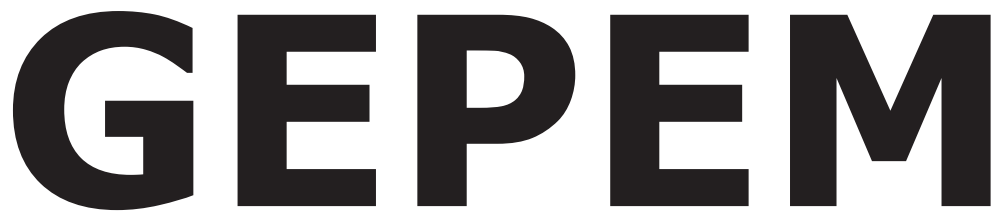

GRUPO DE ESTUdOS E PESQUISAS EM EDUCAÇÃo MATEMÁTICA
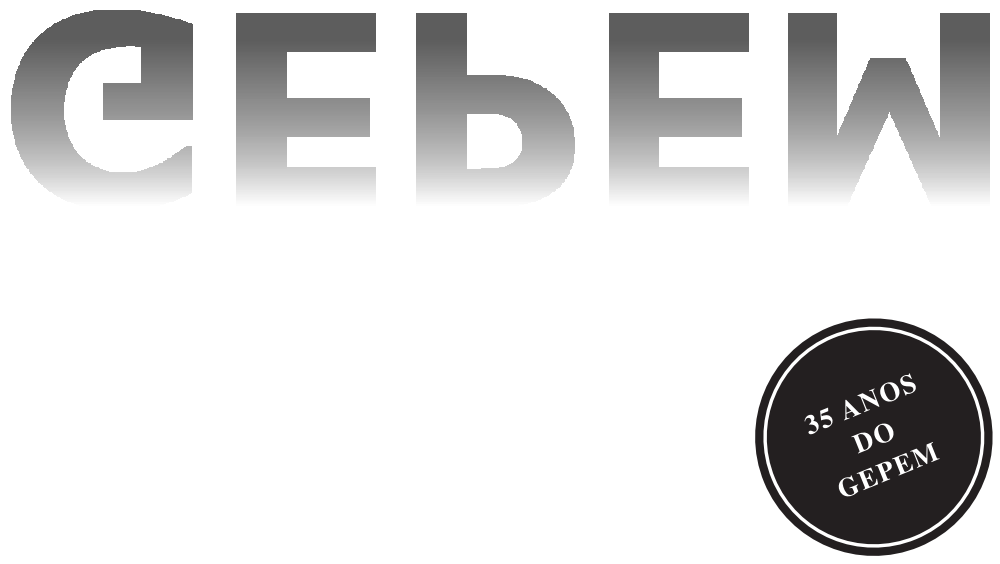

\section{Boletim Gepem}

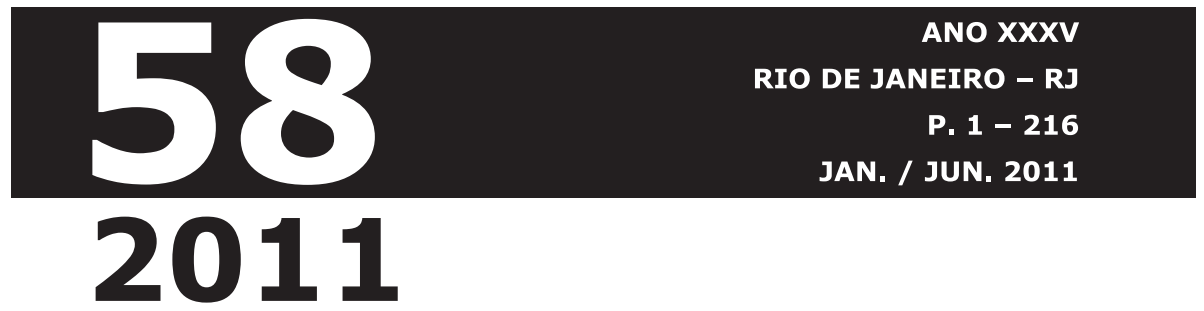

